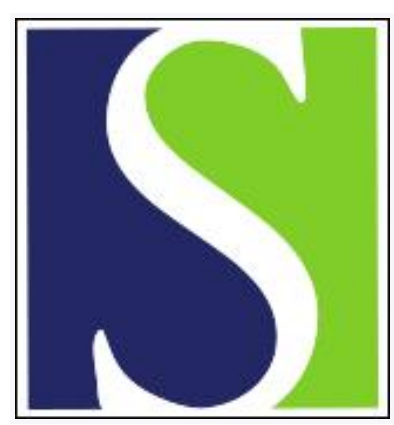

Scand J Work Environ Health 1981;7(4):290-297

https://doi.org/10.5271/sjweh.2545

Issue date: Dec 1981

Emphysema and occupational exposure to industrial pollutants.

by Kjuus $\mathrm{H}$, Istad $\mathrm{H}$, Langård $\mathrm{S}$

Key terms: case-referent study; emphysema; industrial pollutant; occupational exposure; smoking habit

This article in PubMed: www.ncbi.nlm.nih.gov/pubmed/7347914

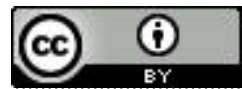




\title{
Emphysema and occupational exposure to industrial pollutants
}

\author{
by Helge Kjuus, MD, ${ }^{1}$ Helge Istad, MD, ${ }^{2}$ Sverre Langård, MD, MSc ${ }^{1}$
}

\begin{abstract}
KJUUS H, ISTAD H, LANGÅRD S. Emphysema and occupational exposure to industrial pollutants. Scand $j$ work environ health 7 (1981) 290-297. In a case-referent study, the possible association between the development of emphysema and occupational exposure to industrial pollutants has been studied. Based on complete work histories from the participants, the number of years of employment in a polluted workplace was assessed for 36 patients with emphysema and 72 referents, matched for age $( \pm 2$ a) and smoking habits. Analyzed as matched triplets, the estimated risk ratio for the exposed ( $\geq 10 \mathrm{a}$ in polluted workplaces) subjects developing emphysema in comparison to the nonexposed $(<10$ a in polluted workplaces) was 3.0 , a value statistically significant. Estimated risk ratios according to the number of years employed in a polluted workplace did not show any significant trend towards a dose-response relationship. Only one of the emphysema patients had never smoked. In the further study of the relationship between emphysema and occupational exposure, the interaction between cigarette smoke and different occupational exposures seems to be of particular interest.
\end{abstract}

Key terms: case-referent study, smoking habits.

Pulmonary emphysema is defined in pathological terms as an increase in the size of air spaces distal to the terminal bronchioles, with destruction of their walls (7). The disease is associated with chronic airflow obstruction and is often associated with chronic bronchitis. The rare homo-

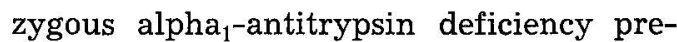
disposes to basal panlobular emphysema, while cigarette smoking may lead to the more common centrilobular form (28). Cigarette smoking has been established as a major causative factor in the development of pulmonary emphysema (1).

The role of occupational exposures in relation to the development of emphysema has been debated for many years. Excess mortality from pulmonary emphysema has been reported for workers in a variety of occupations, among them foundry workers (11), metal molders (30), aluminum workers (27), and welders (26). Cadmium expo-

1 Department of Occupational Medicine, Telemark Sentralsjukehus, Porsgrunn, Norway.

2 Department of Internal Medicine, Telemark Sentralsjukehus, Porsgrunn, Norway.

Reprint requests to: $\mathrm{Dr} \mathrm{H}$ Kjuus, Department of Occupational Medicine, Telemark Sentralsjukehus, Olavsgt 26, N-3900 Porsgrunn, Norway. sure (14, 33), coal mining (31), air pollution (17), and exposure to nitrous fumes (19) have all been associated with emphysema. In animal experiments phosgene (8) and low levels of nitrogen dioxide (13) have been shown to produce the disease. Furthermore, a variety of industrial pollutants have direct toxic effects on pulmonary alveolar macrophages (36). These cells seem to play an important role in the development of emphysema (16).

However, the dominant effect of smoking as risk factor, together with varying diagnostic criteria applied to the term emphysema $(14,34,35)$, make it difficult to evaluate many of the associations previously reported. The question of whether or not chronic exposure to cadmium produces emphysema is still unsettled (34). Chronic bronchitis related to continued inhalation of coal dust over a long period does not seem to be accompanied by emphysema in nonsmokers (29). Except for the association with pneumoconiosis (31), the role of occupational exposures in the development of emphysema still remains unclear.

As most workers are exposed to a variety of occupational pollutants, it 
seems of interest to try to evaluate the total impact of these exposures, in particular in relation to the development of pulmonary diseases. In approaching this problem, the present case-referent study aims to assess whether emphysema occurring among patients in a county hospital is related to occupational exposures at polluted workplaces.

\section{Material and methods}

The study is a prevalence type of casereferent study based on emphysema patients admitted to the medical department of a county hospital. The number of years of employment in a polluted workplace was assessed for each case and for a reference group of nonemphysematous patients in the same department.

\section{Source of subjects}

Male patients below 75 a of age admitted to the medical department of the Telemark County Hospital, Porsgrunn, Norway, during a 2-a period from 1 March 1978 to 1 March 1980 were the source of the subjects for study. The hospital is located in a heavy industry area, with a predominance of chemical industries. To avoid selection with respect to cases referred to the hospital, we did not inform the general practitioners and industrial physicians in the area about the study. Subjects with physical handicaps or mental conditions which would have precluded employment in heavy industry were excluded.

\section{Selection of cases}

The cases were patients admitted to the medical department who were diagnosed as having emphysema. All patients with chronic obstructive lung disease were evaluated as potential cases, irrespective of the previous diagnostic term applied to their condition. The majority of patients had previously been admitted to the hospital however with the diagnosis "chronic bronchitis," "emphysema," "bronchial asthma," or "asthmatic bronchitis." Accepted as cases were patients who met the following criteria:
1. Clinical symptoms and sign:

A history of progressive shortness of breath

Presence of at least four out of eight of the following signs:

Shortness of breath, at rest or during light exertion (walking on level ground at an ordinary pace)

\section{Prolonged expiration}

Hyperresonant percussion note of the chest

Distant or absent breath sounds

Cardiac dulness impaired or absent

Distant heart sounds

Low diaphragm with minimal excursion

Increased anteroposterior diameter of the thoracic cage

2. Lung function tests: More than a 2-SD reduction in the predicted forced expiratory volume in $1 \mathrm{~s}\left(\mathrm{FEV}_{1.0}\right)$ in the highest of at least two satisfactory recordings at the end of the hospital stay.

Radiological signs of emphysema were evaluated for all patients from $35-$ by $-35-\mathrm{cm}$ chest radiographs. As only a proportion of even severe emphysema is recognized radiologically (35), the presence of obvious radiological signs of emphysema was not required for the acceptance of a case. Thus, if a patient fulfilled the clinical and spirometric criteria, he was accepted as a case, even with a radiological description of "clear lung fields." Subjects with radiological signs of pneumoconiosis or other lung diseases were excluded from the study.

The ventilatory tests were performed on a Godart Expirograph (model 16000), which is used for routine spirometry in the medical department. The tests were performed by an experienced nurse, with the patient sitting and wearing a nose clip. Vital capacity (VC) and $\mathrm{FEV}_{1.0}$ were obtained from two satisfactory recordings. All volumes were recorded at body temperature and saturated pressure (BTPS). The predicted normal values for $\mathrm{FEV}_{1.0}$ and the lower limit of the normal values (mean value $-2 \mathrm{SD}$ ) according to age and height were obtained from the data presented by Berglund et al (2). 
Potential cases were subjected to a detailed medical examination of the chest, heart and airways, with special emphasis on the aforementioned clinical signs. A modified Medical Research Council (MRC) questionnaire (21) was used in a personal interview to record respiratory symptoms, past history of chest diseases, and smoking habits.

\section{Selection of referents}

Male patients at the same department without evident lung disease were the source of the reference group. For each patient with emphysema two referents matched for age and smoking habits were selected.

In practice, the procedure was as follows: Every morning one of us (HI) received a list of new patients admitted to the medical department during the last $24 \mathrm{~h}$. After the identification of a case, the first two patients on the list who matched for age were examined for smoking habits. The subsequent diagnostic procedures were the same as for the emphysema cases, except for a simplified ventilatory test in which peak expiratory flow (PEF) was measured with a Wright's Peak Flow

Table 1. Diagnoses of patients in the reference group.

\begin{tabular}{lr}
\hline Diagnosis & Number \\
\hline Myocardial infarction & 15 \\
Angina pectoris & 12 \\
Cardiac arythmia & 6 \\
Other heart disease & 4 \\
Hypertension & 3 \\
Stroke & 4 \\
Deep vein thrombosis & 1 \\
Peptic ulcer & 2 \\
Ulcerative colitis & 2 \\
Gastrointestinal bleeding & 1 \\
Cholelithiasis & 1 \\
Hepatitis & 1 \\
Acute pancreatitis & 1 \\
Acute glomerulonephritis & 1 \\
Pyelonephritis & 2 \\
Diabetes mellitus & 6 \\
Anemia & 2 \\
Polyneuropathy & 2 \\
Fiseumatoid arthritis & 1 \\
Low-back disorders & 4 \\
Tendinitis & 1 \\
\hline Total & 72 \\
\hline
\end{tabular}

Meter. As smokers without evident lung disease have a greater decline in lung function with age than nonsmokers, a normal PEF (lower limit: $90 \%$ of mean value) according to age and smoking habits (12) was the requirement for being a referent. In addition, the referents had to have normal chest radiographs and no signs of obstructive lung disease, judged from the clinical examination and the MRC questionnaire. However, morning cough and sporadic phlegm were accepted.

Several potential referents were rejected because of abnormal $\mathrm{PEF}$ values due to nonrespiratory diseases, eg, cardiac failure referents, who were not accepted due to or poor general health. Some potential referents, who were not accepted due to abnormal PEF values, were evaluated as potential cases, but none of them fulfilled the criteria for being a case. The diagnoses of the patients in the reference group are shown in table 1.

\section{Classification of smoking habits}

From the MRC questionnaire the total number of cigarettes smoked in a lifetime was estimated. For noncigarette smokers one pack of tobacco $(50 \mathrm{~g})$ was estimated to be equal to 50 cigarettes. The cases and referents were matched according to three groups: (i) never smoked, (ii) light smoker $(<150,000$ cigarettes, equals less than 10 cigarettes a day for 40 a), and (iii) heavy smoker ( $>150,000$ cigarettes, equals more than 10 cigarettes a day for 40 a).

By this procedure 36 cases and 72 referents were accepted for study. The ages of the emphysema patients ranged from 48 to 74 a (median 62 a). Among the emphysema patients 29 were classified as heavy smokers, 6 as light smokers, and only 1 had never smoked.

\section{Assessment of exposure}

A complete work history was obtained from all the participants by personal interview. The interview was carried out at the patient's bedside and the interviewer (HK) was not informed beforehand whether the interviewee was a case or referent. No questionnaire was used, and the participants were informed that many patients in the ward, with a variety of 
diseases, were asked for the same information. The purpose of the study was not given. The interview was performed in the last period of the hospital stay, to avoid identification of cases or referents by their acute symptoms at admission. For the same reason interviews in the coronary care unit were avoided. The average length of an interview was $20 \mathrm{~min}$.

Based on the information obtained, all jobs in the subject's work history were classified as either "polluted" or "clean," and the total number of years employed in a polluted workplace was calculated for each subject. A polluted workplace was defined as a place where a subject was regularly exposed to inhaled dust, vapors, or aerosols in his daily work. The classification was made in accordance with a previously prepared job-classification scheme with the most common job types classified into polluted or clean. Examples of the classification are given in table 2 . In many instances, however, a detailed description of the workplace and the actual work done was necessary before classifi- cation could be made. Electricians and carpenters employed in house construction were classified as "clean," while those working in the chemical industry were classified as "polluted." If a job consisted of different tasks, the proportion of time spent in each work type was estimated. If a construction worker spent half his time digging ditches and half operating a machine drill for $10 \mathrm{a}$, the job was classified as "polluted" for 5 a.

Ten or more years in a "polluted" workplace was characterized as "exposed," while less than 10 a in a polluted workplace was characterized as "nonexposed." In each triplet the number of years in polluted jobs was counted up to the year in which the case stopped working or, if he was still employed, up to 31 December 1977.

\section{Statistical methods}

The statistical analyses of the data are based on procedures suggested by Mietti-

Table 2. Examples of the job classification divided into "polluted" and "clean" occupations.

\begin{tabular}{ll}
\hline Polluted & Clean \\
\hline Based upon occupation or workplace & \\
Miner & Farmer \\
Tunnel worker & Lumberjack \\
Welder & Fisherman \\
Plumber & White-collar worker \\
Motor mechanic & Gardener \\
Insulation worker & Teacher \\
Worker in: & Hotel and restaurant worker \\
Chemical industry & Railway worker (rail mender) \\
Iron and steel industry & Watchmaker \\
Foundry & Electrician \\
Shipyard & Carpenter and joiner \\
Cement industry & \\
Roofing felt industry & \\
Mechanical engineering & \\
Sheet metal worker & \\
Baker & \\
Smith & \\
Based upon actual work performed & \\
Seaman (machine worker) & \\
Painter (indoors) & \\
Warehouse worker, cement factory & \\
Crane driver, foundry & \\
Wood processing worker, planning and cutting & Sawmill worker, transport of timber \\
Construction worker, drilling and blasting in & Construction worker, ditch digging and earth \\
work, dusty stone work & moving \\
Bricklayer's helper, cement mixer & Bricklayer \\
Driver (tankers) & Driver (not tankers) \\
\hline
\end{tabular}


nen for the calculation of p-values (22), and for the estimation of risk ratios (23), together with a method for calculating the approximate confidence interval of the risk ratio (25). The effect of retention of the matching as compared to dissolving the matching was evaluated as the quotient of the risk ratios in the unmatched to the matched material (24). In the calculation of the chi-square for trend, "doses" of $\mathrm{x}_{1}=0, \mathrm{x}_{2}=1$ and $\mathrm{x}_{3}=2$ were assigned to the three exposure levels (5).

\section{Results}

The number of years in polluted workplaces ranged from 0 to 46 in the emphysema group (median 22 a), and from 0 to $47 \mathrm{a}$ in the reference group (median $17 \mathrm{a}$ ). In all, $81 \%$ of the cases and $57 \%$ of the referents had been employed in polluted workplaces for ten or more years. Analyzed as matched triplets, the estimated risk ratio for the exposed $(\geq 10$ a in polluted workplaces) subjects developing emphysema compared to the nonexposed $c<10$ a

Table 3. Distribution of exposured ( $\geq 10$ a in a polluted workplace) and nonexposed $(<10 \mathrm{a}$ in a polluted workplace) subjects in 36 triplets.

\begin{tabular}{lrrr}
\hline & \multicolumn{3}{c}{$\begin{array}{c}\text { Number of referents } \\
\text { with exposure }\end{array}$} \\
\cline { 2 - 5 } Emphysema patients & 2 & 1 & 0 \\
\hline Exposed & 9 & 15 & 5 \\
Nonexposed & 2 & 4 & 1 \\
\hline
\end{tabular}

Point estimate of risk ratio: 3.0

$95 \%$ confidence interval: $\quad 1.2-7.5$

$\chi^{2}(1)=5.6 \quad p=0.02$ (two-tailed) in polluted workplaces) was 3.0 (table 3) $\left(\chi^{2}=5.6 \mathrm{p}=0.02\right.$, two-tailed). When the matching was dissolved, a risk ratio of 3.1 was found. An exposed/nonexposed dichotomy at 5 and 15 a of exposure gave a risk ratio of 4.0 and 2.9 , respectively. As the quotient of the risk ratios in the unmatched to the matched material was 1.0 , dissolving the matching seemed acceptable for the further analysis. Estimates of risk ratios according to the number of years employed in a polluted workplace did not show any significant trend towards a doseresponse relationship (table 4).

\section{Discussion}

As pulmonary emphysema is generally defined anatomically, the clinical diagnosis "emphysema" will always be one of uncertainty. This situation applies particularly to our case series, drawn from a county hospital setting without access to advanced diagnostic procedures. Therefore, the nonspecificity in the diagnosis of the disease under study must be considered. As the incidence of emphysema is low, the chance of emphysema patients being included in the reference series was small. However, the occurrence of false-positives in the case series cannot be ruled out. The effect of their inclusion would, however, be one of dilution, with the possibility of masking a real difference between the two groups. Nonemphysematous patients in the case group would influence the estimated risk ratio in a conservative direction and would not explain the actual difference found.

A potential source of selection bias in a study of occupational exposure to in-

Table 4. Number of cases and referents, according to length of stay in a polluted workplace, and estimates of risk ratio.a

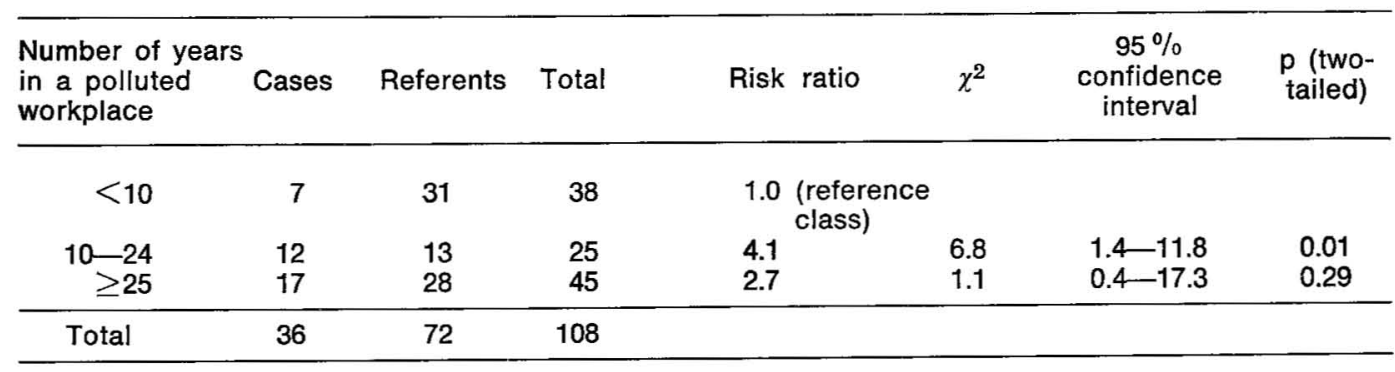

a Test for trend: $\chi^{2}(1)=3.2 p$ (two-tailed) $=0.07$ 
dustrial pollutants is the difference between the groups in recruitment from different geographic areas. As all the patients at the hospital are recruited from the same area, without any known selection of particular diagnostic categories, selection bias from urban/rural differences is not likely to have occurred. Furthermore, as the doctors in the area did not know about the study, selection bias due to the exposurerelated referral of cases to the hospital was expected to be avoided.

Although combined exposures are common in the workplace, little work has been done in the field of occupational health epidemiology on assessing the effects of a multiplicity of exposures (10). Good definition and quantitation of the constituents of a combined exposure are highly desirable, but are in most instances impossible to obtain.

Regarding the present study, the dichotomous division of all job types into "polluted" and "clean" does in fact simplify the variety of occupational exposures to the individual worker, and one can always dispute which jobs should be classified as "polluted" and which jobs as "clean." More serious, however, is the possibility of introducing systematic errors into the process of assessing the exposure.

Although quite detailed guidelines for classification were given by the job classification scheme, an individually detailed description of the workplace and the actual work performed was the basis for some of the decisions. In this process, systematic errors could be introduced at several stages. Patients with emphysema, with accompanying shortness of breath, may have searched their memories more thoroughly than the referents concerning exposure to dust and other pollutants in their past work career. The presence of a "memory bias" cannot therefore be ruled out. However, the participants were not made aware of the purpose of the study, and the classification of the great majority of the jobs could be done according to the job classification scheme, independent of potential biased information from the participants.

Although the interviewer was not informed beforehand whether the interviewee was a case or referent, some emphysema patients with dyspnea at rest were identified as possible cases during the interview. Awareness of this possible bias, however, may just as well have favored an underestimation of the exposure as the opposite. Moreover, the classification of jobs was performed at the end of the study, when previously identified cases had been forgotten.

Another problem in this study relates to the prevalence type of study design. The insidious development of emphysema, together with its low incidence, made an incidence-based approach unfeasible. As the time of diagnosis could not be ascertained exactly, we arbitrarily chose to register possible exposure years within each triplet up to the year the cases stopped working. Alternatively, if 1970 had been chosen as the last year for possible exposure, the estimated risk ratio remained unchanged (3.0).

However, there is still a possibility that the exposure experience both among the cases and the referents could have been influenced by their disease, even in the years before 1970 . If so, the possible changeover to "cleaner" jobs is expected to be more prominent among the cases, having a chronic lung disease with progressive shortness of breath, than among the referents with a variety of more or less acute diseases. Moreover, patients with chronic conditions which could have precluded employment in heavy industry, such as disabling rheumatoid arthritis or juvenile diabetes, were not included in the study.

It is still difficult to evaluate the degree to which insidious shortness of breath changed the actual exposure experience among the cases. No significant trend towards a dose-response relationship was found in this study (table 4). The lower risk ratio found for long exposures could be explained by a possible change to cleaner jobs among the emphysema patients as their symptoms progressed. However, the estimated risk ratios have wide confidence intervals, and in such a small study random variation could explain this finding just as well.

In the present study, $81 \%$ of the cases were heavy smokers and only one patient had never smoked. The strong association which exists between emphysema and smoking makes the latter an important potential confounding factor in this study. 
Although controlled by matching, there might be a suspicion of some remaining confounding effect from smoking within the separate categories, as only three categories were chosen. However, as the average lifetime number of cigarettes smoked was 209,000 among the cases and 214,000 among the referents, the result cannot be explained by different smoking habits in the two groups.

In regard to the pathogenesis of emphysema, an excess release of elastase (4) and an inactivation of alpha $a_{1}$-antitrypsin (18) have been described as responses to cigarette-smoke exposure. The current hypothesis proposes that the balance between elastase activity and its inhibition is altered in cigarette smokers so that part of the lungs is autodigested, with the production of emphysema (18).

Nitrogen dioxide, which is a common constituent of both cigarette-smoke and many industrial pollutants, has been shown to promote the release of protease within the lung (20). The emphysema observed in cadmium-exposed workers has been related to inactivation of alpha $\mathrm{a}_{1}$-antitrypsin by cadmium (6), but this mechanism has not been confirmed by others (3). However, cadmium, as well as nickel, manganese, chromium and vanadium, are shown to be toxic to pulmonary alveolar macrophages, with a possible release of lysosomal enzymes (36).

In regard to the role of industrial pollutants in the development of emphysema, the combined effect of smoking and occupational exposure could be of importance. As smoking impairs long-term dust clearance from the lung (9), the effect of other toxic particles could be aggravated. Furthermore, the synergistic effect of different pollutants upon the lung $(15,32)$ may make the lung tissue extremely vulnerable to the combined effect of smoking and pollutants in the work atmosphere.

The present study indicates that workers employed in polluted workplaces in this industrial area are more prone to developing emphysema than workers employed in clean workplaces. In the further study of the relationship between emphysema and occupational exposure, the interaction between cigarette smoke and different occupational exposures seems to be of particular interest.

\section{Acknowledgments}

We would like to thank Dr S Nyhus for providing patients for the study, Ms A Westlie for her technical assistance with the lung function tests, Ms PA Flor for her linguistic assistance, and Ms U Danielsen for typing the manuscript.

\section{References}

1. Auerbach O, Hammond EC, Garfinkel L, Benante C. Relation of smoking and age to emphysema: Whole-lung section study. $\mathrm{N}$ engl $\mathrm{j}$ med 286 (1972) 853-857.

2. Berglund E, Birath G, Bjure J, Grimby G, Kjellmer I, Sandqvist L, Söderholm B. Spirometric studies in normal subjects: I. Forced expirograms in subjects between 7 and 70 years of age. Acta med scand 173 (1963) 185-192.

3. Bernard A, Roels H, Buchet JP, Lauwerys $R$, Masson $P$. $\alpha_{1}$-antitrypsin in cadmium toxicity: An evaluation of its suggested role. Toxicology 9 (1978) 249-253.

4. Blue M-L, Janoff A. Possible mechanisms of emphysema in cigarette smokers: Release of elastase from human polymorphonuclear leukocytes by cigarette smoke condensate in vitro. Am rev respir dis 117 (1978) 317-325.

5. Breslow NE, Day NE. Statistical methods in cancer research. Volume I: The analysis of case-control studies. International Agency for Research on Cancer, Lyon 1980, pp 146-154. (IARC scientific publications no 32$)$.

6. Chowdury $P$, Louria DB. Influence of cadmium and other trace metals on human $\alpha_{1}$-antitrypsin: An in vitro study. Science 191 (1976) $480-481$.

7. CIBA Guest Symposium. Terminology, definitions, and classification of chronic pulmonary emphysema and related conditions: Report of the conclusions. Thorax 14 (1959) 286-299.

8. Clay JR, Rossing RG. Histopathology of exposure to phosgene: An attempt to produce pulmonary emphysema experimentally. Arch pathol 78 (1964) 544-551.

9. Cohen D, Arai SF, Brain JD. Smoking impairs long-term dust clearance from the lung. Science 204 (1979) 514-517.

10. Cowles SR. Medical effects of combined industrial exposures. J occup med 21 (1979) $413-416$.

11. Egan B, Waxweiler RJ, Blade L, Wolfe J, Wagoner JK. A preliminary report of mortality patterns among foundry workers. J environ pathol toxicol 2 (1980) 259-272.

12. Ferris BG, Anderson DO, Zickmantel $\mathbf{R}$. Prediction values for screening tests of pulmonary function. Am rev respir dis 91 (1965) 252-256. 
13. Freeman G, Haydon GB. Emphysema after low-level exposure to $\mathrm{NO}_{2}$. Arch environ health 8 (1964) 133-136.

14. Friberg L. Health hazards in the manufacture of alkaline accumulators with special reference to chronic cadmium poisoning. Acta med scand suppl 240 (1950) $1-124$.

15. Hazucha M, Bates DV. Combined effect of ozone and sulphur dioxide on human pulmonary function. Nature 257 (1975) $50-51$.

16. Hocking WG, Golde DW. The pulmonaryalveolar macrophage. Second of two parts. $\mathrm{N}$ engl $\mathrm{j}$ med 301 (1979) 639-645.

17. Ishikawa $\mathrm{S}$, Bowden $\mathrm{DH}$, Fisher $\mathrm{V}$, Wyatt JP. The "emphysema profile" in two midwestern cities in North America. Arch environ health 18 (1969) 660-666.

18. Janoff A, Carp $H$, Lee DK, Drew RT. Cigarette smoking inhalation decreased $\alpha_{1}$ antitrypsin activity in rat lung. Science 206 (1979) 1313-1314.

19. Kennedy MCS. Nitrous fumes and coalminers with emphysema. Ann occup hyg 15 (1972) 285-300.

20. Lunan KD, Freeman G. Proteolytic activity in lungs of rats exposed to nitrogen dioxide. In: Mittman C, ed. Pulmonary emphysema and proteolysis. Academic Press, New York, NY 1972, pp 463-470.

21. Medical Research Council. Standardized questionnaires on respiratory symptoms. Br med j 2 (1960) 1665.

22. Miettinen OS. Individual matching with multiple controls in the case of all-or-none responses. Biometrics 25 (1969) 339-354.

23. Miettinen OS. Estimation of relative risk from individually matched series. Biometrics 26 (1970) 75-86.

24. Miettinen OS. Components of the crude risk ratio. Am j epidemiol 96 (1972) 168172.

25. Miettinen O. Estimability and estimation in case-referent studies. Am j epidemiol 103 (1976) 226-235.

Received for publication: 27 April 1981
26. Milham S. Cancer mortality patterns associated with exposure to metals. Ann ny acad sci 271 (1976) 243-249.

27. Milham S. Mortality in aluminum reduction plant workers. J occup med 21 (1979) $475-480$.

28. Mittman C, ed. Symposium: Summary of symposium on pulmonary emphysema and proteolysis. Am rev respir dis 105 (1972) $430-448$.

29. Morgan WKC. Industrial bronchitis. $\mathrm{Br} \mathrm{j}$ ind med 35 (1978) 285--291.

30. National Institute for Occupational Safety and Health. Occupational mortality in the State of California 1959-61. US Department of Health, Education, and Welfare, National Institute for Occupational Safety and Health, Cincinnati, OH 1980, pp 29-36. (DHEW (NIOSH) publ no 80-104).

31. Ryder R, Lyons JP, Campbell H, Gough J. Emphysema in coal workers' pneumoconiosis. Br med j 3 (1970) 481-487.

32. Rylander $R$, Öhrström $M$, Hellström $P \AA$, Bergström R. $\mathrm{SO}_{2}$ and particles - Synergistic effects on guinea-pig lungs. In: Walton WH, ed. Inhaled particles: III. Proceedings of an international symposium. Volume 1. Unwin Brothers, Old Woking, Surrey 1971, pp 535-541.

33. Smith JP, Smith JC, McCall AJ. Chronic poisoning from cadmium fume. $J$ pathol bacteriol 80 (1960) 287-296.

34. Stãnescu D, Veriter C. Frans A, Goncette $L$, Roels $\mathrm{H}$, Lauwerys $\mathrm{R}$, Brasseur $\mathrm{L}$. Effects on lung of chronic occupational exposure to cadmium. Scand $j$ respir dis $\mathbf{5 8}$ (1977) $289-303$

35. Thurlbeck WM, Simon G. Radiographic appearance of the chest in emphysema. Am j roentgenol 130 (1978) 429-440.

36. Waters MD, Gardner DE, Aranyi C, Coffin DL. Metal toxicity for rabbit alveolar macrophages in vitro. Environ res 9 (1975) 3247. 